\title{
DESIGN DE MODA EAD: APLICAÇÃO DO CICLO DE APRENDIZAGEM NA DISCIPLINA DE TEORIA E FUNDAMENTOS DO DESIGN
}

\author{
Gabriel Coutinho Calvi ${ }^{1}$ \\ Dênis Martins de Oliveira ${ }^{2}$ \\ Sandra de Cássia Franchini ${ }^{3}$ \\ DOI: $10.29327 / 3860.13 .23-3$
}

\section{RESUMO}

A pesquisa objetiva analisar a relevância do ciclo de aprendizagem aplicado à disciplina de teoria de fundamentos do design do curso superior de tecnologia em design de moda de uma instituição de ensino superior localizada no noroeste do Paraná. Além disso, o artigo explora o avanço da modalidade à distância em ofertar cursos que contemplam disciplinas de carga horária prática, bem como o surgimento de cursos práticos como é o caso dos cursos de design, mais especificamente do em design de moda. A partir disso, entende-se que cada instituição cria uma metodologia de ensino como estratégia de aprendizagem para gerar o engajamento dos discentes com os conteúdos apreendidos no decorrer das disciplinas. Como resultado da pesquisa, entende-se que utilizar das etapas do ciclo de aprendizagem, proporciona aos alunos a capacidade de aprender, além de criar um propósito para as atividades práticas que exploram as habilidades e competências acadêmicas e profissionais.

Palavras-chave: Design de Moda. Ciclo de Aprendizagem. Educação a Distância.

\footnotetext{
${ }^{1}$ Mestre em Gestão do Conhecimento nas Organizações (Unicesumar), Bacharel em Moda (Unicesumar). Professor do curso de Design de Moda presencial e EaD da Unicesumar.ORCID https://orcid.org/0000-0003$\underline{3336-5033}$

${ }^{2}$ Mestrando em gestão do conhecimento nas organizações (Unicesumar); Graduação em Artes Visuais e Moda (Unicesumar); Professor de Design de Moda na modalidade EaD da Unicesumar.- ORCID https://orcid.org/0000-0002-7225-577X

${ }^{3}$ Mestre em Design (Anhembi Morumbi). Bacharel em moda (Unicesumar). Coordenadora do Curso de Design de Moda na modalidade EaD da Unicesumar. - ORCID https://orcid.org/0000-0001-9606-9202
} 


\title{
EAD FASHION DESIGN: APPLICATION OF THE LEARNING CYCLE IN THE THEORY OF DESIGN THEORY AND FUNDAMENTALS
}

\begin{abstract}
The research aims to analyze the relevance of the learning cycle applied to the discipline of fundamentals theory of design of the college of technology in fashion design of an institution of higher education located in the northwest of Paraná. In addition, the article explores the advancement of distance learning in offering courses that include practical subjects, as well as the emergence of practical courses such as design courses, more specifically in fashion design. From this, it is understood that each institution creates a teaching methodology as a learning strategy to generate the engagement of students with the contents learned during the disciplines. As a result of the research, it is understood that using the stages of the learning cycle, provides students with the ability to learn in addition to creating a purpose for practical activities that explore skills and competencies.
\end{abstract}

Keywords: Fashion Design. Learning Cycle, Distance Education.

\section{INTRODUÇÃO}

Considerando o atual cenário, em termos de avanço, no que diz respeito à oferta de formação acadêmica através de cursos de nível superior da modalidade EaD (Educação a Distância) distribuídos em todo o Brasil, faz-se necessário pensar não só a organização que rege tais cursos, mas, também, na forma como os conteúdos serão trabalhados e disponibilizados ao longo das aulas. Dessa forma, é relevante pensar em estratégias de ensino a fim de encantar os alunos e garantir sua atenção para os conteúdos a serem vistos.

Segundo o Ministério da Educação (MEC) - conforme Decreto 5.622, de 19.12.2005 (que revoga o Decreto 2.494/98), que regulamenta o Art. 80 da Lei 9.394/96 a Lei de Diretrizes e Base da Educação Nacional (LDB) - a Educação a Distância (EaD) é a modalidade educacional na qual a mediação didático-pedagógica nos processos de ensino e aprendizagem ocorre com a utilização de meios e tecnologias de informação e comunicação, com estudantes e professores desenvolvendo atividades educativas em lugares ou tempos diversos. Assim, o número de instituições que oferecem diferentes cursos na modalidade 


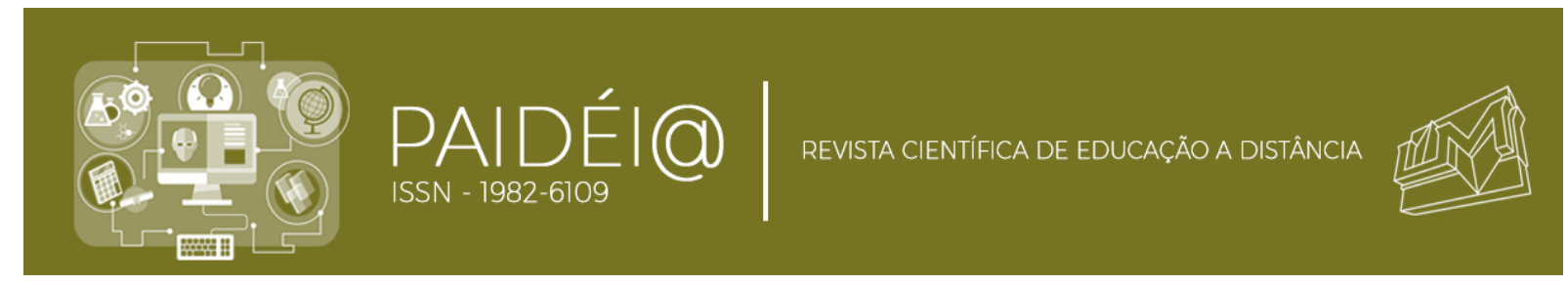

EaD - desde cursos de engenharia até cursos na área de estética, saúde e design - vêm ganhando cada vez mais espaço no território nacional.

Não só a estrutura curricular precisa ser pensada para a oferta dos cursos acima citados. As habilidades do docente $\mathrm{EaD}$ necessitam ser melhor definidas, principalmente daqueles docentes que ministram disciplinas de grande cunho prático como, por exemplo; desenho da figura humana, modelagem tridimensional, modelagem bidimensional, entre outras. Para essas disciplinas, o docente vê-se frente ao desafio de ensinar práticas profissionais, necessária para atuação do discente no mercado de trabalho, por meio de uma câmera, dentro de um estúdio e sem o contato físico com o aluno. Para esta problemática, Martelli (2003) aponta que o ensino e aprendizagem pode ser considerado um movimento dialético entre todos os envolvidos no processo, ou seja - alunos, professores e orientadores. Essa ação descentraliza o professor e torna o aluno como protagonista de sua aprendizagem, onde o docente torna-se um incentivador da aprendizagem.

Considerando as práticas pedagógicas do docente, Tarcia e Cabral (2012) apresentam que, no âmbito da $\mathrm{EaD}$, o docente deve assumir o papel de gestor de situações de aprendizagem utilizando recursos multimidiáticos e construindo processos educativos em ambientes e comunidades virtuais. Neste sentido, o docente passa a utilizar de diversas ferramentas de veiculação de saberes, deixando o papel de transmissor e passando a ser um orientador do processo de ensino e aprendizagem, apoiando os discentes neste processo (BELLONI, 2002).

A partir da premissa que deve se preocupar tanto com a constituição dos conhecimentos dos docentes quanto dos discentes, o MEC (2007) por meio do documento Referenciais de qualidade para a educação a distância, salienta que não há um modelo único de educação a distância e, portanto, os programas apresentam diferentes desenhos e múltiplas combinações de metodologias e recursos educacionais e/ou tecnológicos. Portanto, a natureza dos cursos pode ser estruturada conforme demandas regionais de mão de obra qualificada bem como, necessidades específicas de determinadas áreas do saber, como profissões que exigem o trabalho prático, sendo aspectos que devem ser considerados na definição da metodologia e da tecnologia que será utilizada nos cursos.

Após explanar sobre as diretrizes do MEC, apresenta-se o Curso Superior de Tecnologia (CST) em Design de Moda, objeto da presente pesquisa, que possui em sua matriz curricular disciplinas de caráter prático. Nota-se, a priori, que esses cursos não faziam 


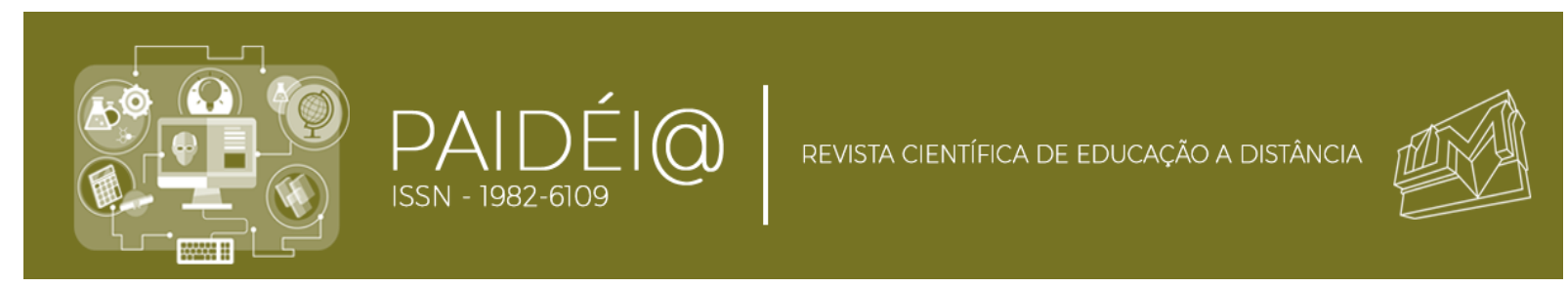

parte dos que eram ofertados na modalidade EaD. Somente com a evolução da modalidade $\mathrm{EaD}$ é que foram repensados e incluídos no projeto, trazendo um novo perfil não só de cursos, mas de metodologias. Embora a modalidade a distância possua características, linguagens e formatos próprios, exigindo administração, desenho, lógica, acompanhamento, avaliação, recursos técnicos, tecnológicos, infraestrutura e pedagógicos condizentes (BRASIL, 2007), foi considerando esses aspectos citados anteriormente que a metodologia de cursos com caráter prático foi estruturada.

Conforme já apresentado, os cursos de engenharias, estética, saúde e design são exemplos desta necessidade de ter adaptações metodológicas, de rever a organização curricular dos cursos e das atividades avaliativas, para que seja possível mensurar o aprendizado dos alunos; como também nas mudanças didáticas onde, cada vez mais, o professor precisa se reinventar para elaborar aulas para serem gravadas em estúdio. Todos estes processos devem ser trabalhados para que ocorra a viabilização de cursos $\mathrm{EaD}$ onde a demonstração de atividades práticas tem grande importância para que haja uma aprendizagem adequada do discente.

Salienta-se que para a presente pesquisa, é analisado o CST em Design de Moda, mais especificamente, a disciplina de Teoria e fundamentos do design verificando quais são as abordagens didáticos pedagógicas utilizadas para significar a aprendizagem dos discentes e, consequentemente, garantir sua aprendizagem.

\section{EDUCAÇÃO A DISTÂNCIA E O ENSINO DO DESIGN DE MODA}

A educação a distância passou a ser utilizada como prática concreta de ensino no Brasil a partir do século XX, sendo uma opção empregada em especial ao ensino de cursos técnicos, de aperfeiçoamento e profissionalizantes. Mas com a regulamentação da prática, em 1996, passou a ter um caráter de efetividade, passando a ser aplicado também ao ensino superior (JESUS; BORGES, 2014).

O conhecimento acerca do uso da web como espaço pedagógico e, consequentemente, educativo, permite pensar sobre o papel das tecnologias, bem como do acesso a tais meios de difusão, em prol da educação e na estruturação dos projetos políticos pedagógicos que atendam a demandas específicas de áreas específicas de todo o território 


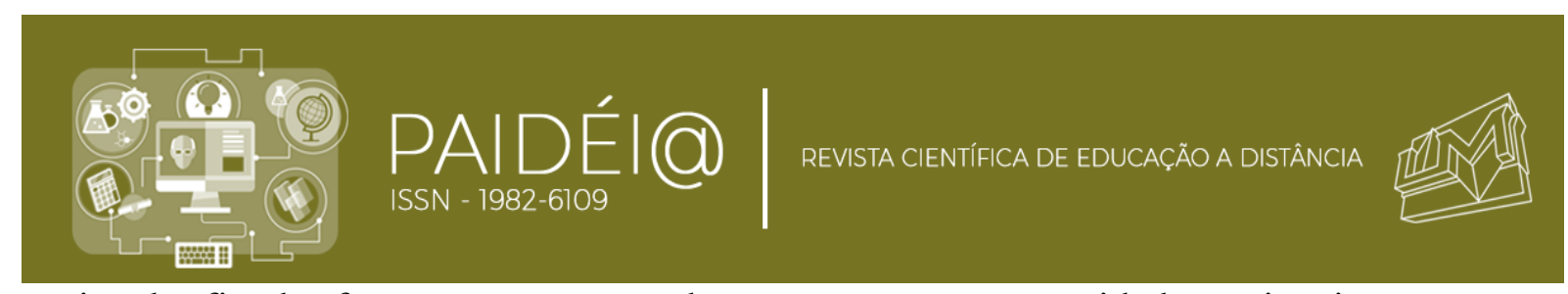

nacional, a fim de ofertar cursos que vão de encontro com as necessidades regionais e possam além de formar indivíduos capacitados para atuação profissional, mudar também as realidades locais, que poderão contar com mão de obra especializada nas mais diferentes áreas (LITTO; FORMIGA, 2009).

Segundo dados da Associação Brasileira de Educação a Distância (ABED) em seu censo referente ao ano de 2018 apresentado em 2019, existe um total 1561 cursos Superiores de Graduação na modalidade Educação a Distância no país. Considerando esse cenário, é importante analisar quais aspectos estruturais são necessários para se manter o funcionamento de cursos $\mathrm{EaD}$ que tenham qualidade em seus programas. A partir daí, podese avaliar a organização curricular de tais cursos, principalmente os tecnólogos, onde a formação é direcionada para atender as demandas mercadológicas específicas.

A partir da apresentação do cenário da $\mathrm{EaD}$, salienta-se que considerar as especificidades de tais cursos é necessário, uma vez que o caráter metodológico de tais cursos possui alguns diferenciais, e levar essas especificidades para a modalidade a distância não é tarefa fácil. A fim de definir a organização dos cursos de cunho tecnológicos o MEC organizou um catálogo nacional de cursos.

Com o propósito de aprimorar e fortalecer os cursos superiores de tecnologia e em cumprimento ao Decreto n ${ }^{\circ} 5.773 / 06$, o Ministério da Educação apresenta o Catálogo Nacional de Cursos Superiores de Tecnologia como guia para referenciar estudantes, educadores, instituições ofertantes, sistemas e redes de ensino, entidades representativas de classes, empregadores e o público em geral (BRASIL, 2010, p. 5).

A partir desta organização, as instituições de ensino superior que ofertam cursos dessa natureza passaram a seguir metodologicamente a estrutura sugerida no catálogo, como guia para pensar seu planejamento curricular, uma vez que o documento ainda ressalta.

O catálogo organiza e orienta a oferta de cursos superiores de tecnologia, inspirado nas Diretrizes Curriculares Nacionais para a Educação Profissional de Nível Tecnológico e em sintonia com a dinâmica do setor produtivo e os requerimentos da sociedade atual. Configurado, deste modo, na perspectiva de formar profissionais aptos a desenvolver, de forma plena e inovadora, as atividades em determinado eixo tecnológico e com capacidade para utilizar, desenvolver ou adaptar tecnologias com a compreensão crítica das implicações daí decorrentes e das suas relações com o processo produtivo, o ser humano, o ambiente e a sociedade (BRASIL, 2010, p. 5). 


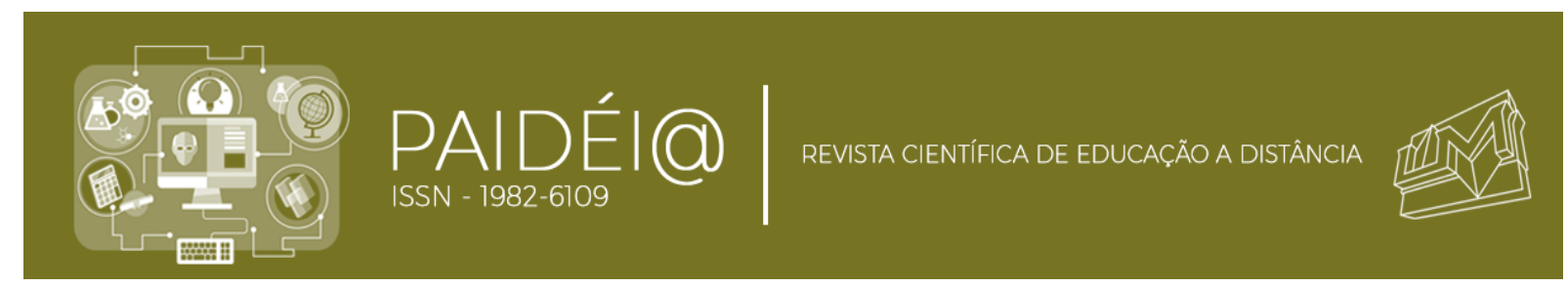

Partindo da premissa em atender a realidade mercadológica, mas acima disso levar um conteúdo de qualidade para a formação do aluno, é que as diretrizes de organização curricular de tais cursos são pensadas. Dessa forma, o Catálogo Nacional de Cursos (CNC) foi atualizado em 2016 e trouxe consigo uma organização por eixos temáticos, onde os cursos de design se encontram; em seu bojo o eixo chamado de Produção Cultural e Design, traz como principal aspecto o seguinte aspecto:

\footnotetext{
O eixo tecnológico de PRODUÇÃO CULTURAL E DESIGN compreende tecnologias relacionadas com representações, linguagens, códigos e projetos de produtos, mobilizadas de forma articulada às diferentes propostas comunicativas aplicadas. Abrange criação, desenvolvimento, produção, edição, difusão, conservação e gerenciamento de bens culturais e materiais, ideias e entretenimento aplicadas em multimeios, objetos artísticos, rádio, televisão, cinema, teatro, ateliês, editoras, vídeo, fotografia, publicidade e projetos de produtos industriais (BRASIL, 2016, p.98)
}

A partir da definição do eixo temático no qual os cursos de Design se encontram, se faz necessário pensar na organização de tais cursos a fim de promover os aspectos de desenvolvimento intelectual e lógico dos indivíduos para que após se formarem, ou seja, após passarem por todas as disciplinas curriculares, estes possam então, exercer suas funções com maestria no mercado de trabalho, desta forma a organização curricular dos cursos abarcados nesta categoria segundo o Brasil (2016) devem contemplar conhecimentos gerais, tais como "Leitura e produção de textos técnicos", "Raciocínio lógico e estético", "Ciência e tecnologia", "Tecnologias de comunicação e informação" e "Normas técnicas".

Para o profissional graduado em design de moda, se faz necessário na própria formação, compreender muito bem os assuntos citados anteriormente, uma vez que caberá a este profissional estruturar os textos técnicos, seja para descrever uma coleção de moda, seja para apresentar um projeto ao cliente, trabalhando assim em sintonia com os elementos tecnológicos e as normas técnicas pertinentes a área de atuação, além da necessidade de atender as demandas estéticas relacionadas ao ato de projetar de maneira lógica e objetiva. Portanto, para que estes assuntos se tornem parte da formação do acadêmico de design de moda, e possam se consolidar em sua prática profissional, há a necessidade de se ter um docente capaz de conduzir o processo de compreensão acerca de tais assuntos.

Os aspectos gerais que norteiam a formação acadêmica do profissional designer de moda apresentados no catálogo nacional de cursos trazem diversos elementos que são 


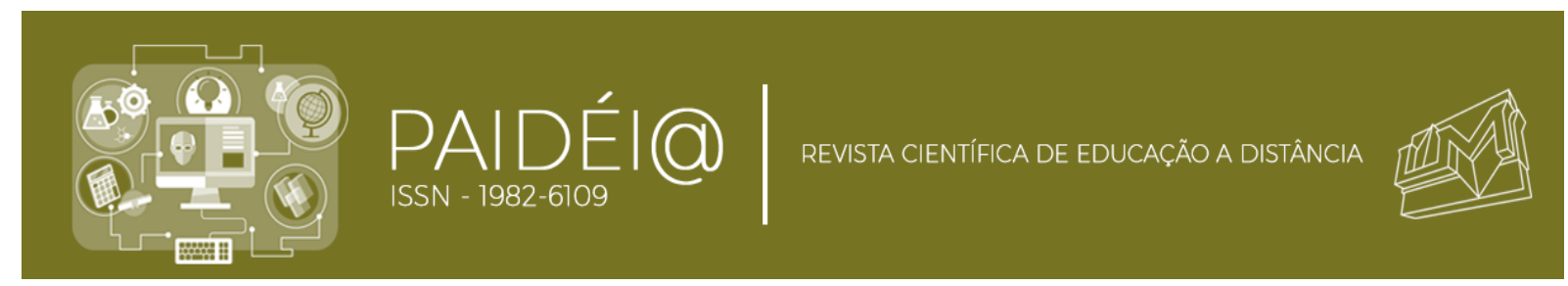

primordiais para qualquer formação de nível superior, mas ainda existem especificidades que são tratadas somente considerando o regionalismo e a necessidade mercadológica de formação qualificada, onde um olhar mais cauteloso se faz necessário para que a formação acadêmica vá de encontro com os anseios das demandas profissionais deste aluno. Dessa forma, apresenta-se as habilidades e competências que o perfil do profissional graduado em design de moda deve apresentar, segundo o CNC:

\begin{abstract}
Criar e desenvolver produtos para a indústria da moda. Analisar e aplicar fatores estéticos, simbólicos, ergonômicos, socioculturais e produtivos. Realizar pesquisa de moda. Planejar, gerenciar e articular coleções de moda com processos de fabricação, matérias-primas e viabilidade técnica e sustentável. Elaborar protótipos, modelos, croquis, fichas técnicas e portfólios com uso de técnicas diferenciadas de expressão gráfica. Avaliar e emitir parecer técnico em sua área de formação (BRASIL, 2016, p.2).
\end{abstract}

A partir das definiçõos estruturantes que regem a formação acadêmica do profissional graduado em design de moda, alguns pontos podem ser analisados no que diz respeito ao perfil profissional que este deve estar apto a exercer no final de sua jornada acadêmica. Portanto, a descrição de Brasil (2016) traz o aspecto do fazer, ou seja, construir, confeccionar algo, como uma atribuição necessária a formação acadêmica para o designer de moda quando este necessita "Elaborar protótipos, modelos, croquis" e "Usar técnicas de expressão gráfica diferenciadas”.

Analisando esses aspectos citados no documento que norteia a formação dos alunos, se faz necessário pensar como tais conteúdos serão levados até esses acadêmicos, considerando a modalidade $\mathrm{EaD}$ e suas barreiras físicas, onde o canal para levar o conteúdo é a internet e o professor precisa apresentar as diferentes formas do "Fazer" com relação ao conteúdo em si para que haja uma formação plena deste aluno.

Assim, embora a modalidade a distância possua características, linguagem e formato próprios, exigindo administração, desenho, lógica, acompanhamento, avaliação, recursos técnicos, tecnológicos, de infra-estrutura e pedagógicos condizentes, essas características só ganham relevância no contexto de uma discussão política e pedagógica da ação educativa. Disto decorre que um projeto de curso superior a distância precisa de forte compromisso institucional em termos de garantir o processo de formação que contemple a dimensão técnico-científica para o mundo do trabalho e a dimensão política para a formação do cidadão (BRASIL, 2007, p. 7). 


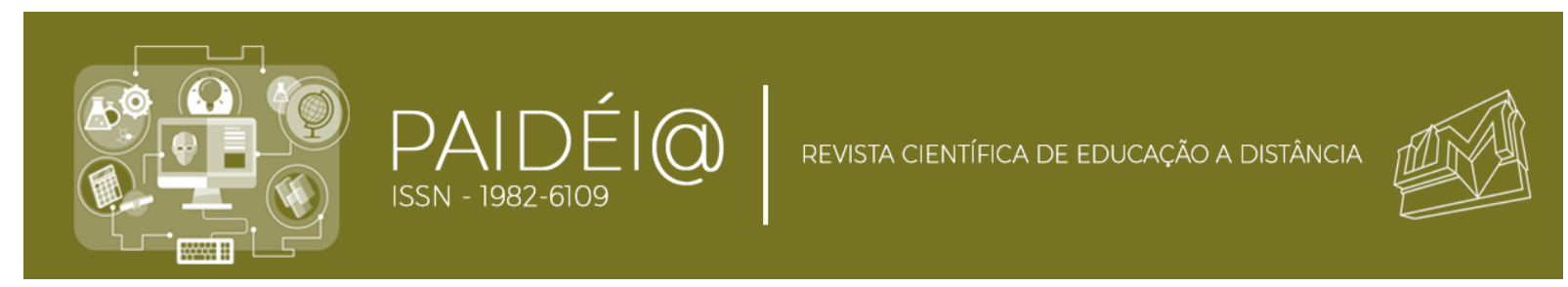

Considerando a autonomia que o documento de Brasil (2007) apresenta, no que diz respeito à organização dos cursos de nível superior com relação a metodologia empregada, entende-se que elaborar recursos de aprendizagem são essenciais para estimular o fazer dos discentes em design de moda. Neste sentido, entra em voga a presente pesquisa que procura analisar as estratégias de aprendizagem do CST em design de moda de uma Instituição de Ensino Superior (IES) privada localizada no noroeste do Paraná.

\section{O CICLO DE APRENDIZAGEM NO CST EM DESIGN DE MODA}

O ciclo de aprendizagem foi desenvolvido pela IES estudo de caso, como estratégia de aprendizagem a fim de que os agente envolvidos na elaboração e criação dos recursos de aprendizagem, sistematizem seus conteúdos e atividades com base no ciclo, para que os discentes passem por todas as etapas de um ensino de qualidade. Dessa forma, o ciclo de aprendizagem possui sete etapas distintas - problematização, significação, experimentação, reflexão, conceitualização, ação e avaliação. A Figura 1 apresenta as características de cada uma das etapas:

Figura 1 - Ciclo de Aprendizagem 

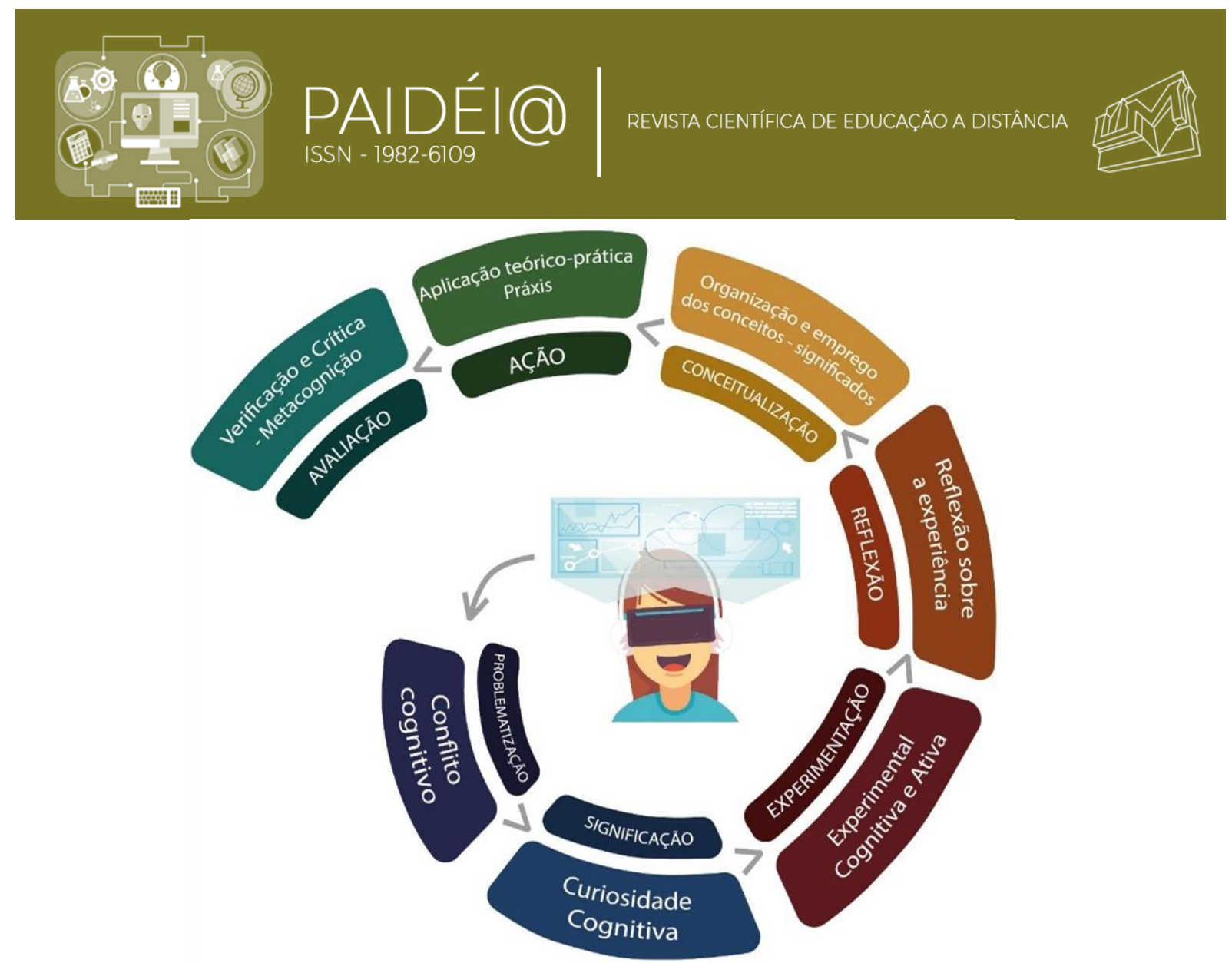

Fonte: Elaborado pela IES estudo de caso (2020)

Cada uma das etapas do ciclo compreende uma etapa na aprendizagem do aluno para que, ao final, ele passe por todas as experiências de aprendizagem. Dessa forma, as aulas, o material didático, as atividades teóricas e práticas ou qualquer objeto de aprendizagem que seja elaborado, deve contemplar as etapas do ciclo. Por exemplo, ao iniciar uma nova disciplina, o docente deve elaborar um roteiro de aula e indicar onde se enquadra cada etapa do ciclo dentro de sua aulas. Essa dinâmica é utilizada para que seja analisado se o ciclo, de fato, é aplicado. O Quadro 1 apresenta as especificidades de cada uma das etapas do ciclo.

Quadro 1 - Características das etapas do ciclo de aprendizagem

\begin{tabular}{|l|l|}
\hline Problematização & $\begin{array}{l}\text { Nesse etapa ocorre a apresentação de um desafio ao aluno seja através de um texto, } \\
\text { um questionamento ou até mesmo em cases. O propósito é provocar o discente } \\
\text { para que ele busque em seu repertório conexões com os conteúdos que são } \\
\text { apresentados e, consequentemente, procurar por novos conhecimentos para } \\
\text { compreender os conteúdos trabalhados. }\end{array}$ \\
\hline Significação & $\begin{array}{l}\text { Para essa etapa há o compromisso com o significado daquilo que será estudado. } \\
\text { Ou seja, após a problematização, é apresentado ao discente a relevância do } \\
\text { conteúdo para sua formação professional e acadêmica. Nesse etapa, ainda, os } \\
\text { conhecimentos prévios dos alunos se fundem aos novos. }\end{array}$ \\
\hline Experimentação & $\begin{array}{l}\text { Etapa onde os discentes fazem a imersão nos conteúdos. Momento de "mão na } \\
\text { massa" e de desenvolvimento das competências profissionais pessoais subsidiada } \\
\text { pelas estratégias de aprendizagem onde os alunos exercitam na prática o que } \\
\text { aprenderam na teoria. }\end{array}$ \\
\hline
\end{tabular}




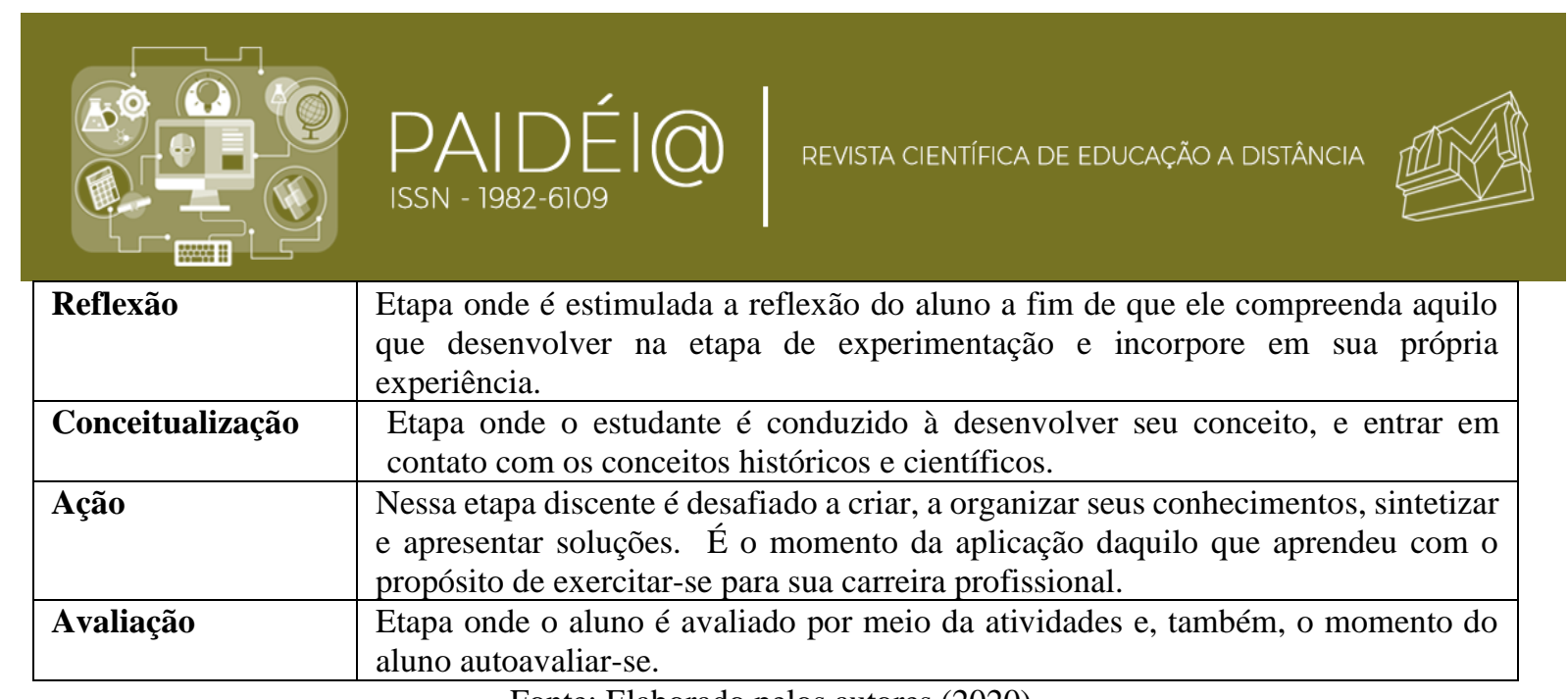

Fonte: Elaborado pelos autores (2020).

A partir da explicitação do ciclo de aprendizagem, salienta-se que em cada etapa o aluno assume o controle da sua aprendizagem, sendo tarefa dos agentes que promovem os conteúdos, seja professores, tutores, coordenadores entre outros, garantir que eles cheguem até o aluno sem nenhum ruído. Além disso, em todas as disciplinas do curso de design de moda, as atividades culminam em uma prática que visa exercer as habilidades e competências dos discentes, preparando-os para o mercado de trabalho.

Para a presente pesquisa analisa-se o ciclo de aprendizagem aplicado na disciplina de teoria e fundamentos do design. O Tópico 3.1 dicorre sobre cada uma das etapas do ciclo e apresenta o resultado das atividades dos alunos.

\subsection{O CICILO DE APRENDIZAGEM E A DISCIPLINA DE TEORIA E FUNDAMENTOS DO DESIGN}

A disciplina de teoria e fundamentos do design tem como propósito levar ao conhecimento do aluno as diversas formas e técnicas para a coleta de informações, as quais serão transformadas em subsídios para o desenvolvimento e criação de produtos de moda. Além disso, a disciplina visa conceituar e estabelecer relações entre arte e moda, trabalhando fundamentos e conceitos de estética, percepção visual, processo criativo, elementos e princípios do design, tendo como foco principal o produto.

Dentro da dinâmica do ciclo de aprendizagem que envolve as etapas de problematização, significação, experimentação, reflexão, conceitualização, ação e avaliação, intenta-se distinguir onde cada etapa do ciclo se enquadra dentro da proposta de ensino e aprendizagem da disciplina. 


\subsubsection{Etapa: Problematização}

Essa etapa acontece dentro da disciplina de teoria e fundamentos do design nos momentos em que são apresentados aos alunos as situações envolvendo a criação e composição de looks e, consequentemente, a identificação do estilo na qual ele se enquadra, exigindo que o discente faça uma leitura visual interpretando os princípios e elementos do design presentes nas peças. A Figura 1 explicita uma parte do processo.

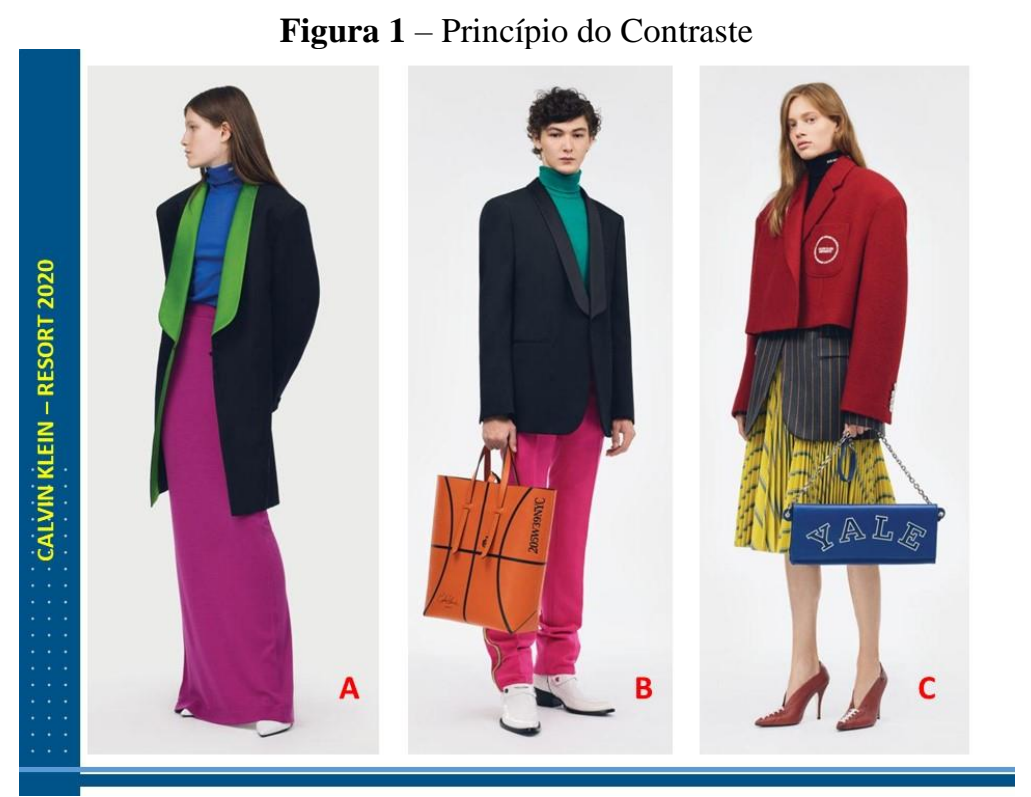

Fonte: Imagens retiradas do Pinterest (2020)

A Figura 1 representa um dos slides utilizados durante as aulas de teoria e fundamentos do design para apresentar a aplicação dos conceitos dos princípios do design. Os looks da coleção da marca Calvin Klein - Resort 2020, remetem ao princípio do contraste devido as cores utilizadas. Ao trazer exemplos utilizando marcas famosas, os discentes podem construir os conhecimentos visualmente e na prática.

\subsubsection{Etapa: Significação}

Ao apresentar os estilos, princípios e elementos do design, enfatiza-se a relevância de se conhecer as características de cada um deles para o processo de alfabetização visual. 


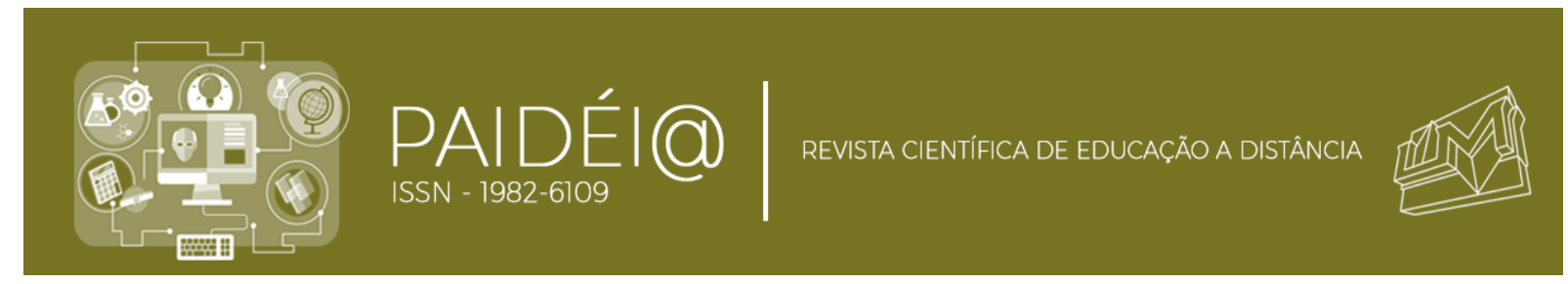

Além disso, ao tratar sobre os mais variados estilos (romântico, minimalista, contemporâneo, entre outros) e sobre os princípios e elementos do design (equilíbrio, contraste, repetição, linha, forma, direção, silhueta, entre outros, são apresentadas coleções de marcas relevantes da atualidade que utilizam dessas referências para a criação das coleções. Ou seja, no decorrer das aulas, os alunos entram em contato com a utilização da teoria em casos práticos.

O exemplo apresentado na Figura 1 possibilitam ao aluno visualizar a aplicação dos princípios do design na prática. Além disso, expõe a relevância de conhecer a teoria para a formação profissional dos discentes e, mais ainda, a criação de um repertório para o desenvolvimento criativo.

\subsubsection{Etapa: Experimentação}

Nessa etapa o discente desenvolve na prática todos os conceitos apresentados nas etapas de problematização e significação. Como estratégia pedagógica para a disciplina destacam-se algumas práticas: A começar pelo quiz contendo quatro questões objetivas relativas aos conteúdos trabalhados nas aulas, para que os alunos possam testar aquilo apreenderam no decorrer dos conteúdos. Além das questões objetivas, o quiz contém uma questão aberta para que o aluno possa deixar suas apreensões sobre a aula e, também, as dúvidas que ficaram em relação ao conteúdo. É pertinente salientar que o Quiz não vale nota.

As outras atividades como o Material de Avaliativo de Aprendizagem Prática (MAPA), Fórum e Atividade de Estudo (AE), são estratégias pedagógicas de aprendizagem. No MAPA os alunos exercem os conhecimentos que apreenderam por meio da técnica de leitura e alfabetização visual. Portanto, ele seleciona um estilo e a partir da identificação de suas características, realiza a customização de um sapato.

As atividades de estudos (AE) são 3 (três), e acontecem no decorrer das quatro semanas de aulas. Elas são divididas em dois momentos; na primeira AE1 é disponibilizado aos alunos uma questão discursiva que tem como objetivo despertar a criticidade e sua capacidade analítico-argumentativa. Ou seja, na AE1 é apresentado uma foto contendo de um look onde o aluno precisa interpretar essa imagem a partir dos conhecimentos apreendidos sobre os princípios e elementos do design. Nas AE2 e AE3, são disponibilizadas respectivamente, dez questões objetivas a respeito dos conteúdos explorados nos recursos de aprendizagem (livro, aulas conceituais e ao vivo). 


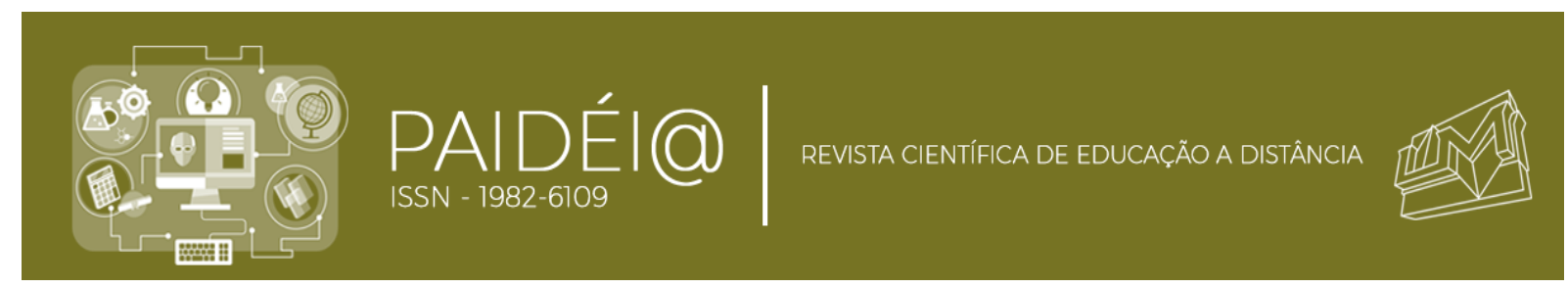

O fórum tem como propósito desenvolver a capacidade do aluno em sintetizar os conteúdos vistos no decorrer da disciplina através de um resumo conceitual (estilo mapa mental), onde ele apresenta os principais pontos presentes no livro didático, aulas conceituais e/ou aulas ao vivo.

\subsubsection{Etapa: Reflexão}

Todas as atividades aplicadas na fase de experimentação conduzem o aluno a reflexão dos conteúdos desenvolvidos na prática (MAPA) e exercitados na dinâmica do quiz, do fórum e das atividades de estudo. Cabe salientar, ainda, que ao final de cada arquivo da atividade MAPA enviado, o aluno pode apresentar sua experiência com a atividade desenvolvida. Essa etapa facilita a reflexão de todo o processo e fomenta o discente a refletir sobre a relevância de se estudar os estilos, princípios e elementos do design.

\subsubsection{Etapa: Conceitualização}

Por meio das ferramentas que a prática disponibiliza - Quiz, Mapa, Fórum e AE - é possível que o discente transcenda o nível da memorização e avance para o nível do conhecimento e da aprendizagem efetiva. Já que todas elas complementam os conceitos apreendidos com os recursos didáticos - livro didático, aulas ao vivo e conceituais.

\subsubsection{Etapa: Ação}

A etapa da ação dentro da disciplina de teoria de fundamentos do design acontece simultaneamente com as etapas de significação e experimentação, pois, no decorrer das aulas são apresentados exemplos concretos do processo de construção de imagens e da narrativa que os desfiles de moda, bem como as coleções de designers nacionais e internacionais possuem.

No MAPA a ação está presente no desafio do aluno em extrair as especificidades que caracterizam a composição dos looks das coleções e, por meio do processo criativo, faça a customização de um sapato considerando os estilos e, também, os princípios e elementos do 
design. Além disso, na etapa de ação do MAPA o aluno desenvolve indiretamente as habilidades de desenho, ergonomia e criatividade, essenciais para a profissão de designer.

\subsubsection{Etapa: Avaliação}

As atividades que são disponibilizadas no decorrer da disciplina de teoria e fundamentos do design asseguram uma formação continuada no decorrer das 4 semanas. Possibilitando que o aluno desenvolva, além do repertório cultural, as habilidades de customizar sapatos/roupas a partir da decodificação de estilos e das particularidades que os princípios e elementos do design abordam, culminando em uma prática avaliativa.

A prova da disciplina é o último estágio do processo de avaliação. É nela que o aluno pode apresentar se o seu engajamento com os estudos foi eficaz ou não. Cabe salientar que a etapa de avaliação não serve apenas para avaliar os alunos, mas também, o corpo docente e todos os materiais que foram disponibilizados para os alunos. Ou seja, os comentários durante as aulas, as participações no Quiz, no Fórum, nas AE's e no MAPA fornecem indiretamente um feedback do que foi positivo ou negativo no decorrer da disciplina e que podem ser potencializados para as próximas.

O MAPA da disciplina de teoria e fundamento do design como mencionado neste tópico é a transformação de um sapato com base nos estilos do design. Além disso, o discente precisa apresentar, ao final da sua criação, quais são os princípios e elementos do design que sua criação apresenta. A Figura 2 apresenta uma montagem de um dos processos criativos dos alunos da disciplina:

Figura 2 - Processo de Customização do Sapato 

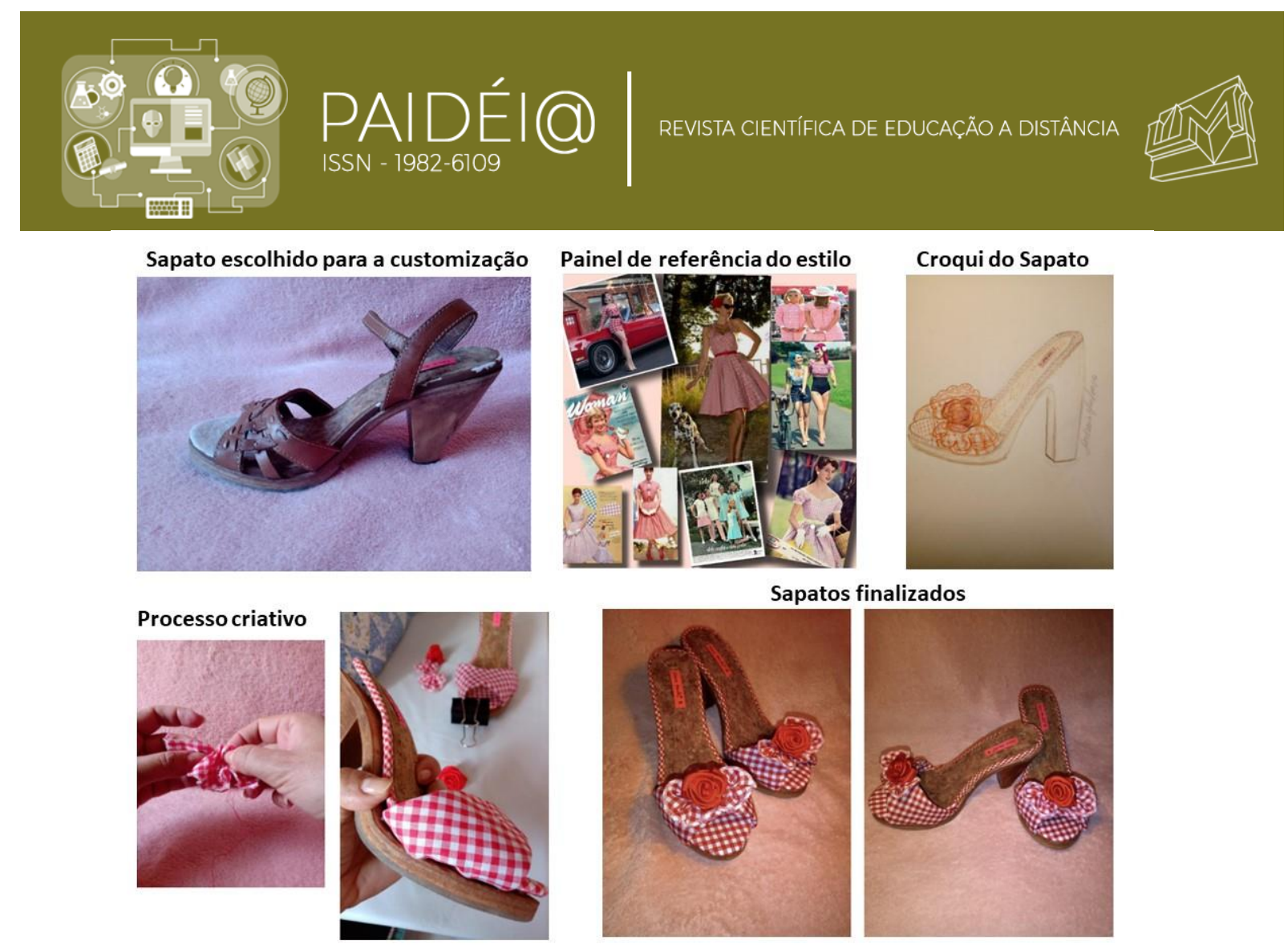

Fonte: Elaborado pelo discente do CST em Design de Moda

Como pode ser observado na Figura 2, para a customização do sapato o aluno dispende de uma série de técnicas e conhecimentos para criar um produto final de acordo com aquilo que foi trabalhado no decorrer das aulas. Dentro do processo de customização envolve o processo criativo, o conhecimento a respeitos dos estilos do design e, também, dos princípios e elementos, além de habilidades manuais para o desenvolvimento do croqui e, também, para a confecção do sapato. Portanto, a atividade de customização envolve mais do que a etapa de experimentação, ela também exige que o aluno explore sua reflexão, conceitualização, ação e avaliação. Ou seja, dentro de uma atividade teórica o aluno visita a maioria das etapas do ciclo de aprendizagem.

Outras disciplinas do CST em Design de moda, também utilizam do MAPA para apresentar trabalhos práticos que permitem que os alunos exercitem suas habilidades e competências. Cabe salientar que, ao final de cada atividade, o aluno pode apresentar como foi sua experiência com a atividade, indicando os prós e contras que encontrou durante o processo. 


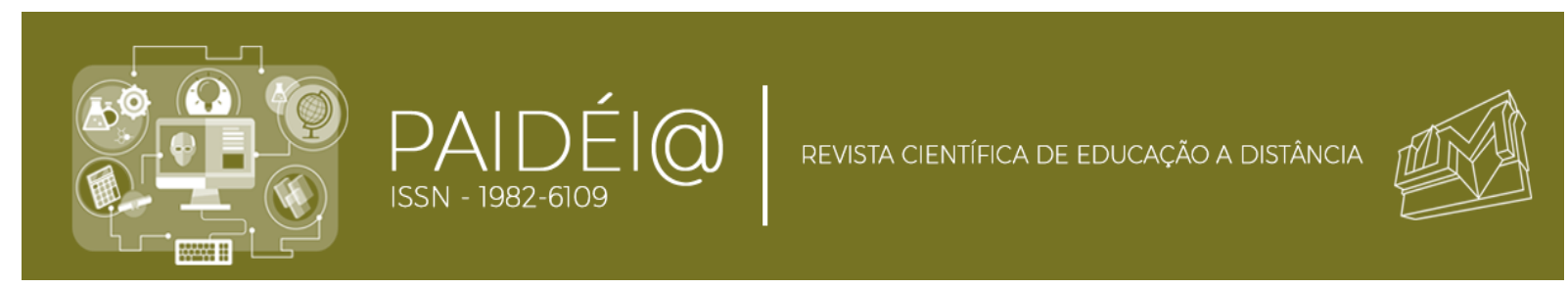

\section{CONSIDERAÇÕES FINAIS}

Com a pesquisa é possível perceber que ao criar sua própria metodologia de aprendizagem, as IES geram engajamento nos discentes potencializando os conhecimentos que eles recebem ao longo do curso. No caso do CST em design de moda, cada uma das atividades desenvolvidas, começando pelo MAPA exploram os discentes de forma que o preparam para sua vida profissional.

O compromisso em desenvolver todos os recursos didáticos como aulas, material didática, livros e atividades, com base no ciclo de aprendizagem, garante que todos os agentes envolvidos no processo pensem nas formas de como os alunos receberão e entrarão em contato com esses recursos. Dessa forma, o ciclo se torna peça chave para que não só a disciplina de teoria e fundamentos do design, como todas as outras disciplinas do curso de design de moda, trabalhem dentro da mesma dinâmica e com os mesmos propósitos.

\section{REFERÊNCIAS}

ABED - Associação Brasileira de Educação a Distância. Censo EAD.BR: Relatório analítico da aprendizagem a distância no Brasil 2017. Curitiba: InterSaberes, 2018.

BELLONI, M. L.. Ensaio sobre a educação a distância no Brasil. Educ. Soc., Abr 2002, vol.23, no.78, p.117-142.

BORGES, E. M.; JESUS, D. P.. A EAD no contexto educacional: propostas para avaliação. Revista Brasileira de Aprendizagem Aberta e a Distância, v. 13, p. 193-209, 2014.

BRASIL, Ministério da Educação. Catálogo Nacional de Cursos Superiores de Tecnologia. Esplanada dos Ministérios, bloco - Brasília/DF, 2016.

BRASIL, Ministério da Educação. Referenciais de qualidade para a educação superior a distância. Secretaria de educação a distância, Brasília, 2007. 
BRASIL, Secretaria de Educação Profissional e Tecnológica. Catálogo Nacional de Cursos Superiores de Tecnologia. Esplanada dos Ministérios, Edifício-Sede Brasília/DF, 2010.

TARCIA, R. M. L.; CABRAL, A. L. T.. O novo papel do professor na EAD. Educação a distância: o estado da arte v 2. São Paulo, Pearson education do Brasil, 2012.

MARTELLI, Ivana. EAD: uma alternativa de políticas educacionais para a formação de professores. Tese apresentada ao Programa de Pós-Graduação da Faculdade de Filosofia e Ciências, Campus de Marília, Universidade Estadual Paulista "Júlio de Mesquita Filho" (UNESP), como requisito parcial à obtenção do Título de Doutor em Educação. Marília 2003. Disponível em

<https://repositorio.unesp.br/bitstream/handle/11449/101535/martelli_i_dr_mar.pdf?seque $\underline{\text { nce }=1>}$ 


\section{Gabriel Coutinho Calvi}

Mestre em Gestão do Conhecimento nas Organizações (Unicesumar), Bacharel em Moda (Unicesumar). Professor do curso de Design de Moda presencial e EaD da Unicesumar.ORCID https://orcid.org/0000-0003-3336-5033

\section{Dênis Martins de Oliveira}

Mestrando em gestão do conhecimento nas organizações (Unicesumar); Graduação em Artes Visuais e Moda (Unicesumar); Professor de Design de Moda na modalidade EaD da Unicesumar.- ORCID https://orcid.org/0000-0002-7225-577X

\section{Sandra de Cássia Franchini}

Mestre em Design (Anhembi Morumbi). Bacharel em moda (Unicesumar). Coordenadora do Curso de Design de Moda na modalidade EaD da Unicesumar. - ORCID https://orcid.org/0000-0001-9606-9202

Artigo recebido em 24/11/2020

Aceito para publicação em 17/12/2020

Para citar este trabalho:

CALVI, Gabriel Coutinho; OLIVEIRA, Dênis Martins de; FRANCHINI, Sandra de Cássia. DESIGN DE MODA EAD: APLICAÇÃO DO CICLO DE APRENDIZAGEM NA DISCIPLINA DE TEORIA E FUNDAMENTOS DO DESIGN. Revista Paidéi@. Unimes Virtual. Volume 13-Número 23. Janeiro-2021. Disponível em:

https://periodicos.unimesvirtual.com.br/index.php/paideia/index 